\title{
The Role of Laboratory Parameters in Assessment of Disease Severity and Outcome in COVID-19 patients - A Retrospective Study in a Tertiary Care Centre in Southern India
}

\author{
Rajeshwari B. ${ }^{1}$, Salapathi Shanmugam ${ }^{1 *}$, Anila Mathan ${ }^{1}$, Dhananjayan $\mathbf{R}^{1}$, Isabella Princess $\mathrm{B}^{1}$, \\ Selvan $K^{2}$ and Mitra Ghosh ${ }^{3}$ \\ ${ }^{1}$ Department of Laboratory Services, Apollo Speciality Hospitals, Vanagaram, Chennai -600095. India \\ ${ }^{2}$ Apollo Preventive Health Check, Gream's Road, Chennai- 600006. \\ ${ }^{3}$ Department of Histopathology, Apollo Specialty Hospitals, Vanagaram, Chennai -600095. India
}

\begin{abstract}
Background: Corona Virus Disease 2019 (COVID19) is a global pandemic, the outbreak of which started in China in December 2019. Apart from the clinical symptoms and pulmonary computed tomography (CT) findings, several laboratory biomarkers also play an important role in management of these patients so that immediate attention can be given to those with severe disease and critical illness. In this study we tried to find the association of various laboratory biomarkers in COVID-19 patients, analyzed around the time of admission, with the severity of the disease and outcome.

Methods: In this study 1048 COVID19 positive cases admitted in our hospital during the study period from April 2020 to October 2020 were included. The cases were clinically assessed based on the severity of the disease at the time of presentation and during the course in hospital and categorized into 3 categories as Mild, Moderate and Severe according to our hospital protocol for management of COVID 19 patients. The clinical and laboratory data were retrieved from electronic medical records. The levels of various laboratory parameters at/ around the time of admission were compared with clinical categories, severity and outcome of the disease.
\end{abstract}

Result: We found a statistically significant association of severity and outcome of COVID-19 with various laboratory parameters. There were significantly higher levels of D-dimer, LDH, CK, CRP, Sr Ferritin, cTnI, NT pro BNP, PCT, IL-6 and lower ALC in non survivors compared to survivors and in severe disease compared to mild disease with a $p$ value of $<0.05$.

Conclusion: In this study we propose that along with the initial clinical assessment, age and concurrent co-morbidities of COVID-19 patients which determine the need for their admission to ICUs, the initial assessment of several laboratory parameters is helpful in triaging the patients who need intensive care so that proper allocation of resources can be done.

\section{Keywords: COVID-19, Computed Tomography, Laboratory Biomarkers, Macrophage Activation Syndrome,} Severe Acute Respiratory Syndrome, SARS -CoV-2

\section{Introduction}

Corona Virus Disease 2019(COVID-19) is a global pandemic, the outbreak of which started in China in December 2019. It is a Severe Acute Respiratory Syndrome (SARS) caused by highly infectious virus which belongs to the family of Group 2B corona viruses and named as Severe Acute respiratory Distress syndrome Corona virus 2 (SARS-CoV-2). Most people with Corona virus infectious disease-2019 (COVID-19) have mild to moderate symptoms and recover after the appropriate medical interventions. However, 15-32 \% develops severe or critical COVID-19 with a case-fatality rate of $1-15 \%{ }^{[1]}$ Since the disease spreads rapidly and causes high mortality in the vulnerable group, it is important to triage these patients into those who need immediate intensive care so that useful allocation of resources can be done. There are previous studies which suggest that apart from the clinical symptoms and pulmonary computed tomography (CT) findings, COVID-19 patients showed fluctuations in various laboratory parameters including complete blood count (CBC) variables, cardiac and coagulation parameters, renal and liver function tests, and inflammation-related factors. ${ }^{[2-4]}$ Laboratory biomarkers play pivotal role in such cases so that immediate attention can be given to those patients with severe disease and critical illness. In this study we tried to find the association of various laboratory biomarkers in COVID-19 patients, analyzed around the time of admission, with the severity of the disease and outcome.

\section{Materials and Methods}

This is a retrospective study conducted at our hospital which included 1048 COVID19 positive cases confirmed 
by Reverse transcriptase- Polymerase Chain Reaction (RTPCR) (test performed on nasopharyngeal and oropharyngeal swab samples, using the TaqPath COVID-19 Combo Kit from Thermo Fisher Scientific which is intended for the qualitative detection of ORF1ab, $\mathrm{N}$ and $\mathrm{S}$ genes of the SARS-CoV-2 genome by RT-PCR), admitted during the study period from April 2020 to October 2020. The cases managed as outpatients and cases discharged against medical advice without follow up were excluded from the study. The cases were clinically assessed based on the severity of the disease at the time of presentation and during the course in hospital and categorized into 3 categories as Mild (A \& B1), Moderate (B2) and Severe (C) respectively according to our hospital protocol for management of COVID 19 patients (Table 1). Mild category was further divided into $\mathrm{A}$ and $\mathrm{B} 1$ subgroups according to age and presence of co-morbidities.

The clinical and laboratory data were retrieved from electronic medical records. Laboratory biomarkers included were D-dimer, Absolute lymphocyte count (ALC), Lactate dehydrogenase (LDH), Serum ferritin (Sr Ferritin), Creatinine kinase (CK), C- reactive Protein (CRP), Troponin I(cTnI), N-terminal pro-B-type natriuretic peptide (NT pro BNP), Interleukin-6(IL-6) and Procalcitonin (PCT). D-dimer levels were estimated by Siemens CA660 analyzer and results were reported as $\mu \mathrm{g} / \mathrm{ml}$ Fibrinogen Equivalent Units (FEU). Blood counts were done by using Sysmex Advia 2120i analyzer. LDH and CK were measured by using DIRUI CS-1300B AutoChemistry Analyzer and Siemens Dimension EXL 200 Chemistry Analyzer respectively. Sr Ferritin, PCT, IL-6, NT pro BNP were analyzed by Siemens ADVIA Centaur XP Immunoassay System and cTnI was determined by using Triage MeterPro. CRP was determined by latex agglutination method using CRP kit by RHELAX CRP (Tulip Diagnostics, India). The levels of these parameters at/ around the time of admission were compared with clinical categories and severity of the disease. Statistical analysis was done using IBM-SPSS20.0 software. Continuous variables were compared by Analysis of variance (ANOVA) test. Categorical variables were expressed as number (percentage) and compared by Chi square test. The results with $p$ value of $<0.05$ were considered significant.

\section{Results}

During the period from April 2020 to October 2020, among the cases presented to the fever clinic and emergency department at our institute, there were 2588 COVID19 positive cases confirmed by RT-PCR, of which 1048 cases were admitted as inpatients and included in the study. The remaining 1540 cases were excluded from the study since these cases were either managed as outpatients or discharged against medical advice without follow up. There were $749(71.5 \%)$ males and $299(28.5 \%)$ females (Figure 1). Males were commonly affected than females with a Male to Female (M: F) ratio of 2.5:1. There were $176(17 \%), 352(34 \%)$ in category B1, 268(25\%) in category B2 and 252(24\%) in category C (Figure 2). Age group ranged from 3 years to 89 years. Mean age was 53.5yrs. There were $717(68.4 \%)$ patients with associated co-morbid conditions like Diabetes Mellitus (DM), Systemic Hypertension (SHT), Chronic kidney disease (CKD), Coronary artery disease (CAD), Chronic pulmonary diseases, Hypothyroidism, Tuberculosis (TB) and Malignancy etc. DM was the commonest co-morbidity which was seen in $512(71.4 \%)$ of patients, followed by SHT in 415 (57.8\%) and CAD in 146 (20.4\%) patients. There was statistically significant association between disease severity and patient age, sex, presence or absence of co-morbidities, mean levels of D-dimer, ALC, LDH, CK, CRP, Sr Ferritin, cTnI, PCT, NT pro BNP and IL-6 $(p=<0.05)$ (Table 2-4). Severity was significantly higher in males, in elderly patients and those with associated comorbid conditions. The severe cases showed significantly higher levels of D-dimer, LDH, CK, Sr Ferritin, CRP, PCT, cTnI, NT pro BNP and IL-6 and lower ALC (Table 3-4). In our study we found that even within the mild category, there was significant difference in various lab parameter levels between Category A and Category B1 (Table 3-4). Mortality was seen in $106(10.1 \%)$ patients during the study period. The mortality was significantly higher in Category C $(58.7 \%)$ compared $0.4 \%$ in category B2. There was no mortality in category A and category B1 patients. The mortality in patients with associated co-morbidities was $12.8 \%$ compared to $4.2 \%$ in those with no associated co-morbid conditions. Among the non survivors, $60.4 \%$ patients had two or more associated co-morbid conditions. We also found significant difference in mean age, presence or absence of co-morbidities, mean levels of D-dimer, ALC, LDH, CK, CRP, Sr Ferritin, cTnI, PCT, NT pro BNP and IL-6 between non survivors and survivors. The non survivors were predominantly elderly males and had significantly high levels of D-dimer, LDH, CK, Sr Ferritin, IL-6, CRP, PCT, cTnI and NT pro BNP and lower ALC compared to survivors (Table 5 - 6).

\section{Discussion}

COVID-19 is a systemic disorder affecting multiple organs. ${ }^{[2]}$ The main pathological changes of COVID19 are lung and immune system damage. ${ }^{[5,6]}$ The pathological features of COVID-19 in lung include diffuse alveolar damage with cellular fibromyxoid exudates, desquamation of pneumocytes and hyaline membrane formation, pulmonary 
Table 1: Clinical criteria for categorization of COVID-19 patients.

\begin{tabular}{|c|c|}
\hline Category & Criteria \\
\hline$A$ & $\begin{array}{l}\text { Age }<60 \text { years, Oxygen saturation }\left(\mathrm{SpO}_{2}\right)>/=94 \% \text { in room air (RA), stable vital signs, and no associated } \\
\text { co-morbidities. }\end{array}$ \\
\hline B1 & $\begin{array}{l}\text { Patient's age }>60 \text { or }<2 \text { years and/or with associated co-morbidities }{ }^{*} \text { and }\left(\mathrm{SpO}_{2}\right)>/=94 \% \text { in } \mathrm{RA} \text { with stable } \\
\text { vital signs. }\end{array}$ \\
\hline B2 & $\begin{array}{l}\text { If on } \mathrm{RA} \text {, respiratory rate }(\mathrm{RR})>24 / \mathrm{min} \text { or } \mathrm{SpO}_{2} 90-93 \% \text {, if on Oxygen }\left(\mathrm{O}_{2}\right) \text { requiring }<5 \text { litre/minute }( \\
40 \% \mathrm{Fio} 2) \text { to maintain } \mathrm{SpO} 2>90 \% \text {. }\end{array}$ \\
\hline$C$ & $\begin{array}{l}\text { If on } \mathrm{RA}, \mathrm{SpO}_{2}<90 \% \text {, if on } \mathrm{O}_{2} \text { requiring }>5 \text { litre/minute or any respiratory support (High Flow nasal cannula } \\
\text { /Non Invasive Ventilation/Ventilation) and those with blood pressure of }<90 / 60 \mathrm{mmHg} \text {, Acute respiratory } \\
\text { distress syndrome (ARDS), end organ damage, severe macrophage activation syndrome (MAS) }\end{array}$ \\
\hline
\end{tabular}

* Co-morbidities include Diabetes Mellitus (DM), Systemic Hypertension (SHT), Chronic kidney disease (CKD), Coronary artery disease (CAD,) Chronic pulmonary diseases (Bronchial asthma, Chronic obstructive pulmonary disease), Hypothyroidism (HYT), Tuberculosis (TB) and Malignancy etc.

Table 2: Comparison of sex distribution, presence of co-morbid conditions and outcome with disease severity.

\begin{tabular}{|c|c|c|c|c|c|}
\hline & Category A & Category B1 & Category B2 & Category C & $P$ value \\
\hline \multicolumn{6}{|c|}{ Sex distribution $(n=1048)$} \\
\hline Males & $100(56.8 \%)$ & $238(67.8 \%)$ & $219(81.7 \%)$ & $192((75.9 \%)$ & 0.000 \\
\hline females & $76(43.2 \%)$ & $113(32.2 \%)$ & $49(16.4 \%)$ & $61(24.1 \%)$ & \\
\hline Total & 176 & 351 & 268 & 253 & \\
\hline \multicolumn{6}{|c|}{ Co-morbidities ( $n=1048)$} \\
\hline Present & 0 & $303(86.3 \%)$ & $197(73.5 \%)$ & $217(85.8 \%)$ & 0.000 \\
\hline Absent & $176(100 \%)$ & $48(13.7 \%)$ & $71(26.5 \%)$ & $36(14.2 \%)$ & \\
\hline Total & 176 & 351 & 268 & 253 & \\
\hline \multicolumn{6}{|c|}{ Outcome $(n=1048)$} \\
\hline Non survivors & 0 & 0 & $1(0.4 \%)$ & $105(41.5 \%)$ & 0.000 \\
\hline Survivors & $176(100 \%)$ & $351(100 \%)$ & $267(99.6 \%)$ & $148(58.5 \%)$ & \\
\hline Total & 176 & 351 & 268 & 253 & \\
\hline
\end{tabular}

Table 3: Comparison of lab parameters with disease severity.

\begin{tabular}{|c|c|c|c|c|c|}
\hline & Category A & Category B1 & Category B2 & Category C & $P$ value \\
\hline \multicolumn{6}{|c|}{ D-dimer $(n=1048)($ Normal : $<0.5 \mu \mathrm{g} / \mathrm{ml}$ FEU) } \\
\hline Normal & $140(79.5 \%)$ & $229(65.3 \%)$ & $130(48.5 \%)$ & $67(26.5 \%)$ & 0.000 \\
\hline High & $36(20.5 \%)$ & $122(34.7 \%)$ & $138(51.5 \%)$ & $186(73.5 \%)$ & \\
\hline Total & 176 & 351 & 268 & 253 & \\
\hline \multicolumn{6}{|c|}{ LDH $(n=866)$ (Normal range : $180-360 \mathrm{U} / \mathrm{L})$} \\
\hline Normal & $105(86.8 \%)$ & $215(79.9 \%)$ & $102(42.3 \%)$ & $46(19.6 \%)$ & 0.000 \\
\hline High & $16(13.2 \%)$ & $54(20.1 \%)$ & $139(57.7 \%)$ & $189(80.4 \%)$ & \\
\hline Total & 121 & 269 & 241 & 235 & \\
\hline \multicolumn{6}{|c|}{ CK $(n=792)$ (Normal range :32 - 294 U/L) } \\
\hline Normal & $88(84.6 \%)$ & $201(84.1 \%)$ & $167(74.2 \%)$ & $164(73.2 \%)$ & 0.011 \\
\hline High & $16(15.4 \%$ & $38(15.9 \%)$ & $58(25.8 \%)$ & $60(26.8 \%)$ & \\
\hline
\end{tabular}




\begin{tabular}{|c|c|c|c|c|c|}
\hline & Category A & Category B1 & Category B2 & Category C & $P$ value \\
\hline Total & 104 & 239 & 225 & 224 & \\
\hline \multicolumn{6}{|c|}{ Sr Ferritin $(\mathrm{n}=906)($ Normal range : $20-250 \mathrm{ng} / \mathrm{ml})$} \\
\hline Normal & $71(55.5 \%)$ & $139(48.3 \%)$ & 61(24.4\%) & $39(16.3 \%)$ & 0.000 \\
\hline High & $57(44.7 \%)$ & $149(51.7 \%)$ & $189(75.6 \%)$ & 201(83.8\%) & \\
\hline Total & 128 & 288 & 250 & & \\
\hline \multicolumn{6}{|c|}{ Procalcitonin $(\mathrm{n}=789)$ (Normal: $<0.5 \mathrm{ng} / \mathrm{ml})$} \\
\hline Normal & $96(96.0 \%)$ & $193(85.0 \%)$ & 199(88.1\%) & $164(69.5 \%)$ & 0.000 \\
\hline High & $4(4.0 \%)$ & $34(15.0 \%)$ & $27(11.9 \%)$ & $72(30.5 \%)$ & \\
\hline Total & 100 & 227 & 226 & 236 & \\
\hline \multicolumn{6}{|c|}{ CRP $(n=989))($ Normal: $<6 m g / L)$} \\
\hline Normal & $120(74.1 \%)$ & $164(49.1 \%)$ & $40(16.1 \%)$ & $25(10.2 \%)$ & 0.000 \\
\hline High & $42(25.9 \%)$ & $170(50.9 \%)$ & $208(83.9 \%)$ & $220(89.8 \%)$ & \\
\hline Total & 162 & 334 & 248 & 245 & \\
\hline \multicolumn{6}{|c|}{ Troponin I(n= 766) (Normal : <0.02ng/ml) } \\
\hline Normal & $72(85.7 \%)$ & $175(76.1 \%)$ & $161(72.5 \%)$ & $120(52.2 \%)$ & 0.000 \\
\hline High & $12(14.3 \%)$ & $55(23.9 \%)$ & $61(27.5 \%)$ & $110(47.8 \%)$ & \\
\hline Total & 84 & 230 & 222 & 230 & \\
\hline \multicolumn{6}{|c|}{ NT pro BNP $(n=173)$ (Normal: $0-125 \mathrm{pg} / \mathrm{ml})$} \\
\hline Normal & 0 & $7(50.0 \%)$ & $25(45.5 \%)$ & $19(18.3 \%)$ & 0.000 \\
\hline High & 0 & $7(50.0 \%)$ & $30(54.5 \%)$ & $85(81.7 \%)$ & \\
\hline Total & 0 & 14 & 55 & 104 & \\
\hline \multicolumn{6}{|c|}{ IL-6 (n= 532) (Normal: <7.0pg/ml) } \\
\hline Normal & $16(94.1 \%)$ & $40(37.7 \%)$ & $57(29.7 \%)$ & $26(12 \%)$ & 0.000 \\
\hline High & $01(5.9 \%)$ & $66(62.3 \%)$ & $135(70.3 \%)$ & $191(88.0 \%)$ & \\
\hline Total & 17 & 106 & 192 & 217 & \\
\hline
\end{tabular}

Table 4: Comparison of mean laboratory parameter with disease severity

\begin{tabular}{|l|l|l|l|l|l|}
\hline \multirow{2}{*}{} & \multicolumn{4}{|l}{ Mean clinical and laboratory parameter with standard deviation in different categories } & P Value \\
\cline { 2 - 6 } & A & B1 & B2 & C & \\
\hline Age (years) & $34.9 \pm 12$ & $56.8 \pm 12.8$ & $55.7 \pm 13.8$ & $59.6 \pm 13.1$ & 0.00 \\
\hline D-dimer $(\mu \mathrm{g} / \mathrm{ml}$ FEU) & $0.5 \pm 0.7$ & $1.0 \pm 4.1$ & $2.0 \pm 7.9$ & $4.1 \pm 10.9$ & 0.00 \\
\hline ALC (cells/cumm) & $1618 \pm 728.8$ & $1523 \pm 733.0$ & $1338 \pm 911.0$ & $1210 \pm 2287.1$ & 0.004 \\
\hline LDH (U/L) & $243.4 \pm 79.5$ & $289.8 \pm 117.0$ & $402.6 \pm 151.6$ & $733.9 \pm 102.4$ & 0.00 \\
\hline CK $(\mathrm{U} / \mathrm{L})$ & $176.1 \pm 263.5$ & $213.0 \pm 295.6$ & $333.1 \pm 895.2$ & $369.4 \pm 779.7$ & 0.02 \\
\hline Sr Ferritin $(\mathrm{ng} / \mathrm{ml})$ & $263.9 \pm 398.0$ & $473.2 \pm 882.8$ & $682.6 \pm 826.1$ & $1084.4 \pm 2120.2$ & 0.00 \\
\hline IL-6 $(\mathrm{pg} / \mathrm{ml})$ & $4.9 \pm 7.2$ & $25.7 \pm 49.5$ & $34.8 \pm 55.8$ & $350.0 \pm 2190.1$ & 0.00 \\
\hline
\end{tabular}

Table 5: Comparison of clinical and laboratory data between survivors and non survivors.

\begin{tabular}{|l|l|l|l|}
\hline \multicolumn{2}{|l|}{ Survivors } & Non survivors & P value \\
\hline Sex distribution $(\mathrm{n}=1048)$ & \multicolumn{2}{l|}{} \\
\hline Males & $670(71.1 \%)$ & $79(74.5 \%)$ & 0.000 \\
\hline Females & $272(28.9 \%)$ & $27(25.5 \%)$ & \\
\hline Total & $\mathbf{9 4 2}$ & $\mathbf{1 0 6}$ & \\
\hline
\end{tabular}




\begin{tabular}{|c|c|c|c|}
\hline & Survivors & Non survivors & $P$ value \\
\hline \multicolumn{4}{|c|}{ Co-morbidities(n = 1048) } \\
\hline Present & $625(66.3 \%)$ & $92(86.8 \%)$ & 0.000 \\
\hline Absent & $317(33.7 \%)$ & $14(13.2 \%)$ & \\
\hline Total & 942 & 106 & \\
\hline \multicolumn{4}{|c|}{ D Dimer $(n=1048)$} \\
\hline Normal & $538(57.1 \%)$ & $28(26.4 \%)$ & 0.000 \\
\hline High & $404(42.9 \%)$ & $78(73.6 \%)$ & \\
\hline Total & 942 & 106 & \\
\hline \multicolumn{4}{|c|}{$\operatorname{LDH}(\mathrm{n}=866)$} \\
\hline Normal & $451(58.4 \%)$ & $17(18.1 \%)$ & 0.000 \\
\hline High & $321(41.6 \%)$ & $77(91.9 \%)$ & \\
\hline Total & 772 & 94 & \\
\hline \multicolumn{4}{|c|}{ CK $(n=792)$} \\
\hline Normal & $559(80.0 \%)$ & $61(65.6 \%)$ & 0.006 \\
\hline High & $140(20.0 \%)$ & $32(34.4 \%)$ & \\
\hline Total & 699 & 93 & \\
\hline \multicolumn{4}{|c|}{ Sr Ferritin $(n=906)$} \\
\hline Normal & $296(36.7 \%)$ & $14(14.1 \%)$ & 0.000 \\
\hline High & $511(63.3 \%)$ & $85(85.9 \%)$ & \\
\hline Total & 807 & 99 & \\
\hline \multicolumn{4}{|c|}{ Procalcitonin $(n=789)$} \\
\hline Normal & $584(84.8 \%)$ & $68(68.0 \%)$ & 0.000 \\
\hline High & $105(15.2 \%)$ & $32(32.0 \%)$ & \\
\hline Total & 689 & 100 & \\
\hline \multicolumn{4}{|c|}{ CRP $(n=989)$} \\
\hline Normal & $337(38.0 \%)$ & $12(11.9 \%)$ & 0.000 \\
\hline High & $551(62.0 \%)$ & $89(88.1 \%)$ & \\
\hline Total & 888 & 101 & \\
\hline \multicolumn{4}{|c|}{ Troponin I $(n=766)$} \\
\hline Normal & $491(73.5 \%)$ & $37(37.8 \%)$ & 0.000 \\
\hline High & $177(26.5 \%)$ & $61(62.2 \%)$ & \\
\hline Total & 668 & 98 & \\
\hline \multicolumn{4}{|c|}{ NT pro BNP $(n=173)$} \\
\hline Normal & $49(37.4 \%)$ & 0 & 0.000 \\
\hline High & $82(62.6 \%)$ & $42(100.0 \%)$ & \\
\hline Total & 131 & 42 & \\
\hline \multicolumn{4}{|c|}{ IL-6 $(n=532)$} \\
\hline Normal & $136(30.8 \%)$ & $3(3.3 \%)$ & 0.00 \\
\hline High & $305(69.2 \%)$ & $88(96.7 \%)$ & \\
\hline Total & 441 & 91 & \\
\hline
\end{tabular}


Table 6: Comparison of mean value with standard deviation in survivors and non survivors

\begin{tabular}{|l|l|l|l|}
\hline Parameter & Disease outcome & P value \\
\hline & Survivors(n=942) & Non-Survivors(n=106) & \\
\hline Age (years) & $52.3 \pm 15.5$ & $62.8 \pm 12.5$ & 0.007 \\
\hline D-dimer $(\mu \mathrm{g} / \mathrm{ml} \mathrm{FEU)}$ & $1.5 \pm 5.5$ & $6.3 \pm 15.5$ & 0.000 \\
\hline ALC (cells/cumm) & $1471 \pm 1397.2$ & $1033 \pm 615.7$ & 0.000 \\
\hline LDH (U/L) & $360 \pm 174.2$ & $1007.5 \pm 2451.1$ & 0.000 \\
\hline CK (U/L) & $270 \pm 402.5$ & $537.3 \pm 1535.3$ & 0.000 \\
\hline Sr Ferritin $(\mathrm{ng} / \mathrm{ml})$ & $538.2 \pm 747.4$ & $1545.3 \pm 3173.3$ & 0.000 \\
\hline IL-6 $(\mathrm{pg} / \mathrm{ml})$ & $60 \pm 263.5$ & $650 \pm 3322.3$ & 0.000 \\
\hline
\end{tabular}

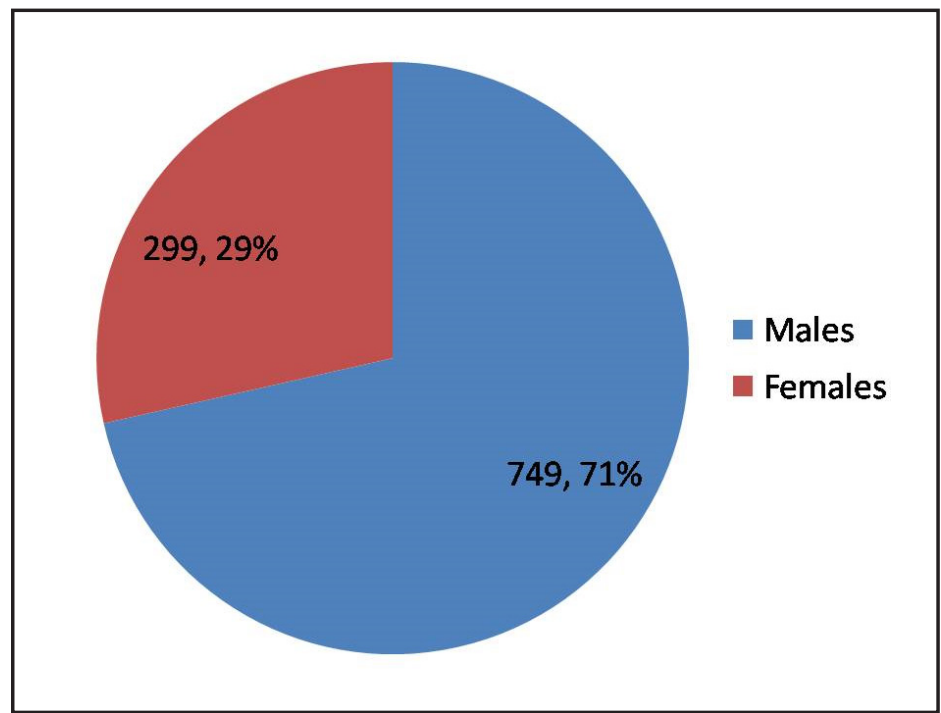

Fig. 1: Sex distribution of COVID-19 cases in the present study.

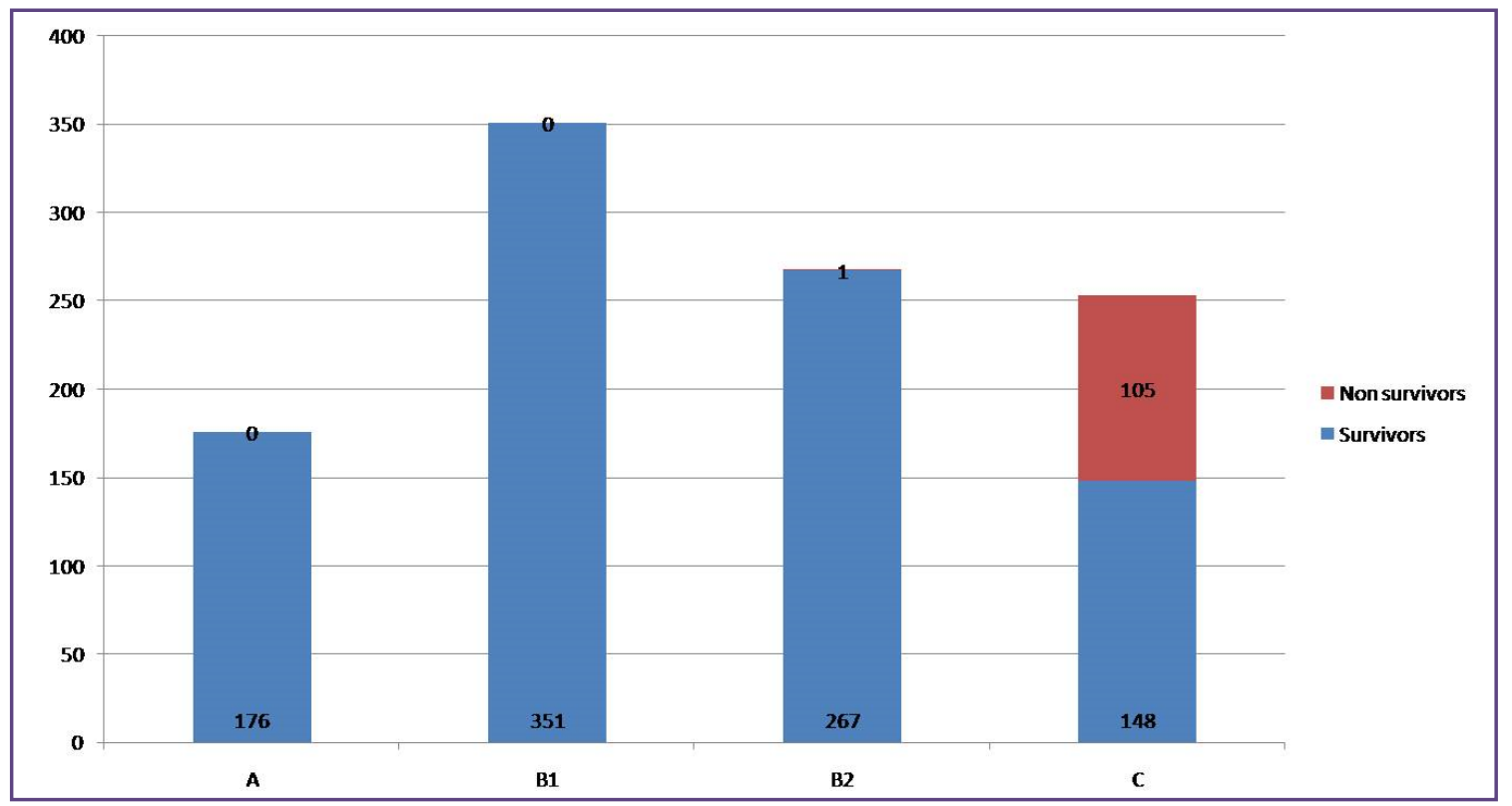

Fig. 2: Distribution of COVID-19 cases among various categories in the present study. 
edema and interstitial mononuclear inflammatory infiltrates. ${ }^{[7]}$ Previous studies have suggested that the elderly and those with underlying diseases are susceptible to COVID-19 infection, and more likely to become critical cases. ${ }^{[8,9]}$ This may be due to age related structural and functional changes in the respiratory tract, causing decreased lung function, altered pulmonary remodeling, diminished regeneration and enhanced susceptibility to pulmonary disease. ${ }^{[10]}$ It is also reported that the older patients have a higher risk of ARDS development. ${ }^{[11]}$

In this study we included 1048 COVID 19 positive patients confirmed by RT-PCR, admitted in our hospital. There was significant association between disease severity and patient age, sex, presence of co-morbid conditions. The severity was significantly higher in elderly, male sex and those with associated co-morbid conditions similar to the study conducted by Tang $\mathrm{N}$ et al. ${ }^{[12]}$ In their study mean age of COVID positive patients was 54.1 years and $41.0 \%$ of them had chronic diseases, as compared to mean age of 53.5 years and $68.4 \%$ patients had co-morbidities in our study. We found significantly higher mean age in non survivors (62.8 years) than survivors (53.5years) comparable to their study. ${ }^{[12]}$ Zhou and others showed older age as a potential risk factor for COVID-19 patients. ${ }^{[13]}$ The in-hospital mortality of severe and critically ill patients with COVID-19 could be up to almost $40 \%$. [14] The mortality in our study was $10.1 \%$. In our study mortality was significantly high in patients with associated co-morbid conditions (12.8\%) compared to in those with no associated co-morbid conditions $(4.2 \%)$. DM was the commonest co-morbidity in non survivors followed by SHT and CAD. In the study of Deng et al ${ }^{[10]}$ hypertension, lung disease, and heart disease were commonest co-morbidities in non survivors. They also found that non survivors had more than one co-morbidity similar to our study.

D-dimers are one of the fragments produced when plasmin cleaves fibrin to break down clots. Any pathologic nonpathologic process (like deep vein thrombosis/pulmonary embolism, arterial thrombosis, disseminated intravascular coagulation, and conditions such as pregnancy, inflammation, cancer, chronic liver diseases, post trauma and surgery status, and vasculitis etc), that increases fibrin production or breakdown also increases plasma D-dimer levels. ${ }^{[15]}$ The D-dimer elevation is probably due to hyperfibrinolysis and increased inflammatory burden induced in SARS-COV-2 infection. ${ }^{[16]}$ In the present study, the D-dimer levels at/around the time of admission were significantly associated with disease severity. The non survivors had significantly high D-dimer levels $(6.3 \mu \mathrm{g}$ / $\mathrm{ml}$ FEU) compared to survivors $(1.5 \mu \mathrm{g} / \mathrm{ml} \mathrm{FEU})$. This was similar to study conducted by Tang $\mathrm{N}$ et al. ${ }^{[12]}$
In the present study, lymphopenia was significantly associated with disease severity. Patients who had severe COVID-19 had significantly lower lymphocyte counts than those with milder disease. This was similar to findings of Velevan TP et al. ${ }^{[17]}$ In a meta-analysis conducted by Ghahramani et $\mathrm{al}^{[2]}$ it was showed that the significant decreased levels of lymphocyte count in severe patients compared to non-severe ones. The mechanism of this lymphopenia is probably due to the cytotoxic action of virus and can be attributed to more decrease in $\mathrm{T}$ cell and especially $\mathrm{T}$ helper cells in severe cases of COVID-19. ${ }^{[2]}$

In our study there was significantly high levels of LDH, CK, CRP, Sr Ferritin, cTnI , NT pro BNP and PCT and IL-6 in non survivors compared to survivors . Garcia et al also found significant differences in laboratory values on admission, between the non-survivor and survivor group. Similar to our study, they showed higher values of $\mathrm{CK}, \mathrm{LDH}, \mathrm{CRP}$ and lower absolute lymphocyte counts in non survivors. ${ }^{[18]}$ Han et al ${ }^{[19]}$ compared LDH with other prognostic biomarkers including CRP and absolute lymphocyte count in predicting severe COVID-19 cases in patients with various levels of COVID-19 severity and demonstrated that LDH had higher accuracy. Shi et al [20] demonstrated that high LDH level was an independent risk factor for the exacerbation in mild COVID-19 patients. Our findings also show that severity of COVID-19 was significantly associated with elevated LDH levels.

Our analysis demonstrated significant increase in CK levels in severe cases than in mild cases. Mao et al, in their study, attributed the muscle symptoms to skeletal muscle injury and damage caused by significantly elevated proinflammatory cytokines. ${ }^{[21]}$ However, Vacchiano et al. found in 108 Covid-19 patients that muscle pain was not associated with CK high levels, supporting the notion that this symptom was not directly accounted for by muscle injury and making a direct viral mechanism unlikely. ${ }^{[21]}$

We found significantly elevated Sr Ferritin levels in severe disease and in non survivors. Similar to our study, elevated ferritin levels due to secondary hemophagocytic lymphohistiocytosis (sHLH) and cytokine storm syndrome have also been reported in severe COVID-19 patients. ${ }^{[17]}$ Circulating ferritin level increases during viral infections and can be a marker of viral replication. ${ }^{[22]}$ Hyperferritinemia caused by the excessive inflammation due to the infection is associated with high mortality, and can be used as an indication to recognize high-risk patients to guide the therapeutic intervention to control inflammation. ${ }^{[23]}$ In our study, COVID-19 patients who were at higher risk because of the co-morbidities showed significantly higher level of Sr Ferritin than in COVID-19 patients without the co- 
morbidities (Table 3) similar to findings of meta analysis conducted by Cheng L et al. ${ }^{[24]}$

In our study there was significant association between severity of COVID 19 and levels of cTnI and NT pro BNP. NT pro BNP assay were mostly done for patients with moderate to severe disease in our study. Cardiac injury is a common condition among the hospitalized patients with COVID-19. ${ }^{[25]}$ The elevated levels of cTnI can be explained by myocardial damage induced by the SARS-CoV-2 infection which has also been demonstrated in previous studies. ${ }^{[26,27]}$ Another possibility could be interstitial infiltration of mononuclear cells instead of direct damage of myocardium in severe cases. ${ }^{[2]}$ In the study by Gao L et al, ${ }^{[25]}$ severe COVID-19 patients with high NTpro BNP levels were older with increased cardiac injury markers and higher levels of systematic inflammation markers similar to our study. They proposed that NTpro BNP is secreted in response to increased myocardial wall stress. Other factors like invasion cardiomyocytes via the binding site of angiotensin-converting enzymerelated carboxypeptidase (ACE2), the pulmonary infection induced inadequate oxygen supply to the myocardium and the influences of cytokine storm syndrome contributing to the cardiac injury, ${ }^{[25]}$ thus causing elevation of NT-pro BNP and risks of poor prognosis in patients with COVID-1925. In the study by Chen et al, ${ }^{[28]}$ patient age, male sex, elevated cTnI, and NT-pro BNP, elevated High sensitive (hs) CRP, elevated serum creatinine, hypertension, and coronary heart disease (CHD) were significantly correlated with critical disease status. They showed that elevated cTnI and CHD were the independent risk factors of critical disease status. They proposed that COVID-19 can significantly affect the heart function and lead to myocardial injury. However, meta-analysis conducted by Ghahramani et al ${ }^{\text {[2] }}$ did not find significant higher level of myocardial enzymes in severe compared to non-severe cases. They found a positive association between inflammatory/ infection markers (ESR, CRP, LDH, and PCT, but not IL-6), coagulation function tests (fibrinogen, PT, and D-dimer) and the COVID-19 severity.

CRP levels are correlated with the level of inflammation, and its concentration level is not affected by factors such as age, sex, and physical condition. ${ }^{[5]}$ In the study conducted by Wang L, ${ }^{[5]}$ CRP levels were positively correlated with lung involvement and disease severity. Another study by Chan JF et al showed that elderly COVID 19 patients have higher CRP levels. ${ }^{[29]}$ Similar to previous studies ${ }^{[5]}$, our study found that the CRP levels were higher in the severe disease category compared to the mild disease category at the time of admission.
Similar to our study, several studies reported that elevated PCT levels are positively associated with the severity of COVID-19. ${ }^{[30,31]}$ A meta-analysis by Lippi $\mathrm{G}$ et al also demonstrated that increased PCT values are related to a 5-fold higher risk of severe SARS-CoV-2 infection. [32] PCT, which is the 116-amino acid precursor of the hormone calcitonin, is normally synthesised and released by thyroid parafollicular $\mathrm{C}$ cells. However, it can also be synthesised in many extrathyroid tissues during bacterial infection, which is mediated by increased concentrations of tumour necrosis factor-alpha (TNF $\alpha$ ) and IL-6. ${ }^{[33]}$ PCT levels appear to be disease severity-dependent and may be associated with bacterial co-infection. ${ }^{[33]}$ We found significantly elevated levels of IL-6 in severe cases and in non survivors which can be explained by a viral-induced hyperinflammatory response with multiorgan involvement due to a cytokine cascade caused by COVID 19. ${ }^{[34]}$

To summarize, in this study we found a statistically significant association of severity and outcome of COVID-19 with D-dimer, LDH, CK, CRP, Sr Ferritin, cTnI, NT pro BNP, PCT, IL-6 and lower ALC. Among these D-dimer, LDH, Sr Ferritin and CRP were more commonly associated with disease severity.

\section{Conclusion}

COVID 19 is a rapidly evolving disease the outcome of which is highly variable and it is still unknown even in the vulnerable group why the severity of the disease varies from one case to other. In this study we propose that along with the initial clinical assessment, age and concurrent comorbidities, of COVID-19 patients which determine the need for their admission to ICUs, the initial assessment of several laboratory parameters is helpful in triaging the patients who need intensive care. Clinicians should consider lymphopenia and the elevated serum levels of LDH, CRP, CK, D-dimer, Sr Ferritin, PCT, cTnI, NT pro BNP and IL-6, for triaging of COVID- 19 patients so that immediate intensive care can be given to those with severe disease and useful allocation of resources can be done.

\section{Acknowledgements}

We sincerely acknowledge Ms Dharani, physician assistant, who assisted in data retrieval. We also acknowledge our technical supervisors Ms Elizebeth, Mr Ventatesan and other technical staff, Ms Geetha, Ms Jayapriya and Mr Mahendra Prabhu, for their technical help.

\section{Funding}

Nil

\section{Competing Interests}

Nil 


\section{References}

1. Chen N, Zhou M, Dong X, Qu J, Gong F, Han Y, et al. Epidemiological and clinical characteristics of 99 cases of 2019 novel coronavirus pneumonia in Wuhan, China: a descriptive study. Lancet 2020;395:507-13.

2. Ghahramani S, Tabrizi R, Lankarani KB.,Amin Kashani SM, Rezaei S, Zeidi N, et al. Laboratory features of severe vs. non-severe COVID-19 patients in Asian populations: a systematic review and meta-analysis. Eur J Med Res $2020 ; 30$.

3. Jin YH, Cai L, Cheng ZS, Cheng H, Deng T, Fan YP, et al. A rapid advice guideline for the diagnosis and treatment of 2019 novel coronavirus (2019-nCoV) infected pneumonia (standard version). Military Med Res 2020;7:4.

4. Vakili S, Savardashtaki A, Jamalnia S, Tabrizi R, Nematollahi MH, Jafarinia M, et al. Laboratory fndings of COVID-19 infection are conficting in diferent age groups and pregnant women: a literature review. Arch Med Res 2020;51:603-7.

5. Wang L. C-reactive protein levels in the early stage of COVID-19. Med Mal Infect. 2020;50: 332-4.

6. General office of the national health commission of China. Covid-19 diagnostic and therapeutic regimen (trial 7th, edition). J Cardiopulm Rehabil Prev 2020;39:103-7.

7. Channappanavar R, Perlman S. Pathogenic human coronavirus infections: causes and consequences of cytokine storm and immunopathology. Semin Immunopathol. 2017;39:529-39.

8. Shang W, Li Y, Li H, Li W, Li C, Cai Y, et al. Correlaion between laboratory parameters on admission and outcome of COVID-19 in maintenance hemodialysis patients. Int Urol Nephrol. 2021;53:165-9.

9. Huang C, Wang Y, Li X et al (2020) Clinical features of patients infected with 2019 novel coronavirus in Wuhan, China. Lancet 2020;395:497-506.

10. Deng Y, Liu W, Liu K, Fang YY, Shang J, Zhou L et al. Clinical characteristics of fatal and recovered cases of coronavirus disease 2019 in Wuhan, China: a retrospective study, Chinese Medical Journal 2020;133:1261-7

11. Ely EW, Wheeler AP, Thompson BT, Ancukiewicz M, Steinberg KP, Bernard GR. Recovery rate and prognosis in older persons who develop acute lung injury and the acute respiratory distress syndrome. Ann Intern Med 2002; $136: 25-36$

12. Tang N, Li D, Wang X, Sun Z.J Abnormal coagulation parameters are associated with poor prognosis in patients with novel coronavirus pneumonia. J. Thromb Haemost. 2020;18:844-7.

13. Borobia AM, Carcas AJ, Arnalich F, Alvarez-Sala R, Monserrat- Villatoro J, Quintana M, et al. A cohort of patients with COVID-19 in a major teaching hospital in Europe. J Clin Med 2020;9:E1733.

14. Dong X, Sun L, Li Y. Prognostic value of lactate dehydrogenase for in-hospital mortality in severe and critically ill patients with COVID-19. Int J Med Sci. 2020 ;17:2225-31.

15. Linkins LA, Takach Lapner S. Review of D-dimer testing: good, bad, and ugly. Int J Lab Hematol. 2017;39(S1):98103.

16. Yao, Y, Cao J, Wang Q, Shi Q, Liu K, Luo Z, et al. D-dimer as a biomarker for disease severity and mortality in COVID-19 patients: a case control study. J. Intensive care 2020;8:49.

17. Velavan TP, Meyer CG. Mild versus severe COVID-19: Laboratory markers. Int J Infect Dis. 2020 Jun;95:304-307.

18. Garcia-Tardon N, Abbes AP, Gerrits A, Robbert J, Slingerland RJ, Besten G. Laboratory parameters as predictors of mortality in COVID-19 patients on hospital admission. Journal of Laboratory Medicine 2020;44:357-9.

19. Han Y, Zhang H, Mu S, Wei W, Jin C, Tong C, et al. Lactate dehydrogenase, an independent risk factor of severe COVID-19 patients: a retrospective and observational study. Aging. 2020;12:11245-58.

20. Shi J, Li Y, Zhou X, Zhang Q, Ye X, Wu Z, et al. Lactate dehydrogenase and susceptibility to deterioration of mild COVID-19 patients: a multicenter nested case-control study. BMC med. 2020;18:168.

21. Rivas-Garcia S, Bernal J, Bachiller-Corral J. Rhabdomyolysis as the main manifestation of coronavirus disease 2019 . Rheumatology (Oxford). 2020;59(8):2174-6.

22. Li Y, Hu Y, Yu J, Ma T. Retrospective analysis of laboratory testing in 54 patients with severe or critical-type 2019 novel coronavirus pneumonia. Lab Invest. 2020;100:794-800.

23. Kernan KF, Carcillo JA. Hyperferritinemia and inflammation. Int Immunol. 2017;29:401-9.

24. Cheng L, Li H, Li L, Liu C, Yan S, Chen H|, et al. Ferritin in the coronavirus disease 2019 (COVID-19): A systematic review and meta-analysis. J clin lab Anal 2020;34:e23618.

25. Gao L, Jiang D, Wen XS, Cheng XC, Sun M, He B, et al. Prognostic value of NT-proBNP in patients with severe COVID-19. Respir Res. 2020;21:83.

26. Zhang F, Yang D, Li J, Gao P, Chen T, Cheng Z, et al. Myocardial injury is associated with in-hospital mortality of confrmed or suspected COVID19 in Wuhan, China: a single center retrospective cohort study. med Rxiv. 2020;

27. Wang D, Hu B, Hu C, Zhu F, Liu X, Zhang J, et al. Clinical characteristics of 138 hospitalized patients with 2019 novel coronavirus-infected pneumonia in Wuhan, China. JAMA. 2020;323:1061-9.

28. Chen C, Chen C, Yan JT, Zhou N, Zhao JP, Wang DW. Analysis of myocardial injury in patients with COVID-19 and association between concomitant cardiovascular diseases and severity of COVID-19. Zhonghua Xin Xue Guan Bing Za Zhi. 2020;48:567-71.

29. Chan JF, Yuan S, Kok KH, To KK, Chu H, Yang J, et al. A familial cluster of pneumonia associated with the 2019 
novel coronavirus indicating person-to-person transmission: a study of a family cluster. Lancet 2020;395:514-23.

30. Zhang JJ, Dong X, Cao YY, Yuan YD, Yang YB, Yan YQ, et al. Clinical characteristics of 140 patients infected with SARS-CoV-2 in Wuhan, China. Allergy 2020; 75: 1730-41.

31. Lu R, Zhao X, Li J, Niu P, Yang B, Wu H, et al. Genomic characterisation and epidemiology of 2019 novel coronavirus: implications for virus origins and receptor binding. Lancet 2020;395:565-74.
32. Lippi G, Plebani M. Procalcitonin in patients with severe coronavirus disease 2019 (COVID-19): a metaanalysis. Clin Chim Acta 2020;505:190-1. doi: 10. 1016/j. cca.2020.03.004.

33. Hu R, Han C, Pei S, Yin M, Chen X. Procalcitonin levels in COVID-19 patients. Int J Antimicrob Agents 2020 ;56:106051.

34. Lipworth B, Chan R, Lipworth S, Kuo CR. Weathering the cytokine storm $n$ susceptible patients with severe SARS-CoV-2 infection. J Allergy Clin Immunol Pract 2020;8:1798-1801.

*Corresponding author:

Dr. Salapathi S, Associate consultant, Department of Laboratory services, Apollo speciality hospitals, Vanagaram. Ayanambakkam Chennai - 600095

Phone: +919159150815

Email: salapsdr@gmail.com

Date of Submission $\quad: 12 / 05 / 2021$

Date of Final Revision : 16/06/2021

Financial or other Competing Interests: None.

Date of Acceptance : 28/06/2021

Date of Publication : 30/07/2021 